\title{
Transcriptome Analysis of the Grape-Elsinoë ampelina Pathosystem Reveals Novel Effectors and a Robust Defense Response
}

\author{
Zhi Li, ${ }^{1,2}$ Ya Wang, ${ }^{1,2}$ Yanchun Fan, ${ }^{3}$ Bilal Ahmad, ${ }^{1,2}$ Xianhang Wang, ${ }^{4}$ Songlin Zhang, ${ }^{1,2}$ Yanxun Zhu, ${ }^{1,2}$ \\ Linlin Gao, ${ }^{1,2}$ Pingping Chang, ${ }^{1,2}$ and Xiping Wang ${ }^{1,2,+}$ \\ ${ }^{1}$ State Key Laboratory of Crop Stress Biology in Arid Areas, College of Horticulture, Northwest A\&F University, Yangling, \\ Shaanxi 712100, China \\ ${ }^{2}$ Key Laboratory of Horticultural Plant Biology and Germplasm Innovation in Northwest China, Ministry of Agriculture, Northwest \\ A\&F University, Yangling, Shaanxi 712100, China \\ ${ }^{3}$ College of Forestry, Northwest A\&F University, Yangling, Shaanxi 712100, China \\ ${ }^{4}$ College of Enology, Northwest A\&F University, Yangling, Shaanxi 712100, China
}

Accepted 30 September 2020.

\begin{abstract}
Elsino $\ddot{e}$ ampelina is an ascomycetous fungus that causes grape anthracnose, a potentially devastating disease worldwide. In this study, a dual RNA-seq analysis was used to simultaneously monitor the fungal genes related to pathogenesis and grape genes related to defense during the interaction at $2,3,4$, and 5 days postinoculation. Consistent with their potential roles in pathogenicity, genes for carbohydrate-active enzymes, secondary metabolite synthesis, pathogen-host interaction, and those encoding secreted proteins are upregulated during infection. Based on Agrobacterium tumefaciens-mediated transient assays in Nicotiana benthamiana, we further showed that eight and nine candidate effectors, respectively, suppressed BAX- and INF1-mediated programmed cell death. The host response was characterized by the induction of multiple defense systems against $E$. ampelina, including synthesis of phenylpropanoids, stilbenes, and terpenoid biosynthesis, cell-wall modifications, regulation by phytohormones, and expression of defense-related genes. Together, these findings offer new insights into molecular mechanisms underlying the grapeE. ampelina interaction.
\end{abstract}

Sequence data for the genome of Elsinoë ampelina in this study has been deposited at GenBank under the accession number SMYM0000. The YL-1 genome sequence data has been deposited at the DDBJ/ENA/GenBank database under the accession number SMYM00000000 (BioProject: PRJNA526997, BioSample: SAMN11125508). Raw RNA-Seq data have been deposited in the National Center for Biotechnology Information Sequence Read Archive under the accession number PRJNA526817.

${ }^{\dagger}$ Corresponding author: X. Wang: wangxiping@nwsuaf.edu.cn

Funding: This work was supported by the National Natural Science Foundation of China (32072534), the Shanxi National Science Foundation grant number 2020JM-155, and the Program for Innovative Research Team of Grape Germplasm Resources and Breeding grant number 2013KCT-25.

*The $\boldsymbol{e}$-Xtra logo stands for "electronic extra" and indicates there are supplementary tables and a supplementary figures file published online.

The author(s) declare no conflict of interest.

(c) (1) () $\odot$ Copyright $\odot 2021$ The Author(s). This is an open access article distributed under the CC BY-NC-ND 4.0 International license.
Keywords: dual RNA-seq, effector, genome annotation, host defense response, pathogenicity, Vitis vinifera

Grapevine (Vitis vinifera) is an important fruit crop used for products such as table grapes, wine, and dried raisins, and it represents a source of nutrients that are beneficial for human health (Pezzuto 2008). However, grapevine production can be severely affected by several fungal diseases that cause a loss of quality and yield (Agudelo-Romero et al. 2015). A notable example is the filamentous ascomycete fungus Elsinoë ampelina, the causal agent of anthracnose disease. Molecular data indicate that the Elsino $\ddot{e}$ genus, of the Myriangiales order, includes 75 species (Fan et al. 2017), many of which are phytopathogens of economically important fruit trees. In addition to grape anthracnose, examples include citrus (genus Citrus) scab caused by E. fawcettii and E. australis, apple (genus Malus) and pear (genus Pyrus) scab caused by E. pyri, and avocado (Persea americana) scab caused by E. perseae.

Grape anthracnose occurs worldwide, particularly in areas with high humidity during the growing season (Magarey et al. 1993). E. ampelina mainly infects young tissues such as tendrils, rachises, leaves, petioles, stems, and berries to produce spot lesions (Barros et al. 2015; Santos et al. 2017). Morphology is characterized by slow-growing colonies, septate hypha, as well as cylindrical and hyaline conidia ( 3 to 6 and 2 to $8 \mu \mathrm{m}$, respectively) (Kono et al. 2009). Hyphae of E. ampelina degrade the cuticle of young leaves, penetrate the cell walls, and then enter the host cell (Braga et al. 2019; Z. Li et al. 2019b). Symptoms are characterized by brown sunken lesions on young leaves and dark brown spots on the berries.

E. ampelina is a fungus of Ascomycetes, Pezizomycotina, Dothideomycetes, Dothidemycetidae, Myriangiales, Elsinoaceae, and Elsinö̈. The order Myriangiales together with Dothideales and Capnodiales form the subclass Dothideomycetidae, which, together with the Pleosporomycetidae form the Dothideomycetes class of ascomycetes (Schoch et al. 2006). In the Dothideomycetidae, five species of Dothideales and 41 species of Capnodiales have been sequenced to date, including Aureobasidium pullulans varieties (Gostinčar et al. 2014), Pseudocercospora fijiensis (Chang et al. 2016), Cladosporium fulvum, and Dothistroma septosporum (de Wit et al. 2012). In the genus Elsinö̈ of order Myriangiales, only three species, 
E. ampelina, E. fawcettii, and E. australis (Jeffress et al. 2020; Li et al. 2020; Shanmugam et al. 2020), have been subjected to genome sequencing. However, little is known about the genome of E. ampelina, especially in identification of pathogenicityrelated genes. To date, most studies have focused on isolation, identification, and pathogenicity testing (dos Santos et al. 2018b; Fan et al. 2017; Poolsawat et al. 2010; Santos and Spósito 2018), morphological characterization and sporulation induction (dos Santos et al. 2018a; Li et al. 2018), infection processes (Braga et al. 2019; 2020; Z. Li et al. 2019b), screening of resistant grape materials (Barros et al. 2015; Kono et al. 2013; Poolsawat et al. 2012; Wang et al. 1998), and comparative expression analysis of resistance-related genes between susceptible and resistant cultivars (Gao et al. 2012; Louime et al. 2011). The molecular mechanisms underlying the pathogenicity of E. ampelina are still poorly understood.

Identification of virulence factors of phytopathogenic fungi can provide important foundations for understanding their pathogenic mechanism, such as carbohydrate-active enzymes (CAZymes), plant cell wall-degrading enzymes (PCWDEs), toxic metabolites, and effectors. Most studies have focused on effectors of phytopathogenic fungi and their interactions with proteins in host plants. Effectors as pathogen-produced molecules that suppress pathogen-associated molecular pattern (PAMP)-triggered immunity and cause effector-triggered susceptibility (Vleeshouwers and Oliver 2014). Genome-wide identification of effectors have become available for various pathogens. For the grape-downy mildew pathosystem, previous genome analyses of Plasmopara viticola have investigated candidate effectors (Brilli et al. 2018; Yin et al. 2017), including RxLR effectors associated with Plasmopara viticola infection (Lan et al. 2019). Genetic improvement of effectors has contributed to disease resistance breeding. However, compared with other major fungal pathogens of grape, information related to E. ampelina is scarce.

So far, no information has been reported about transcripts of E. ampelina in infected grape leaves. Here, a dual transcriptomic analysis was performed to understand the fungal pathogenicity and host defense strategies during interaction between E. ampelina and V. vinifera (Supplementary Fig. S1). This study represents a major step toward completing our understanding of the expression profile of pathogenicity-related genes of E. ampelina during the infection process and provides evidence that supports the virulence function of candidate effectors.

\section{RESULTS}

\section{Pathogenicity of $E$. ampelina.}

Expression profile of $\mathrm{E}$. ampelina during infection of grape leaves. To investigate the gene expression of E. ampelina, we performed RNA-seq profiling of E. ampelina YL-1 at 2, 3, 4, and 5 days postinoculation (dpi) during its infection of V. vinifera cv. Red Globe leaves (Fig. 1A). Light microscopy and transmission electron microscopy confirmed that E. ampelina conidia had germinated and infected the grape leaves at harvest (Fig. 1B, C, and D).

In total, $384.29 \mathrm{~Gb}$ of sequence data were generated from four samples, resulting in $582.29 \pm 44.49,158.55 \pm 15.73$, $57.58 \pm 4.19$, and $55.56 \pm 4.75$ million clean reads for each replicate (Supplementary Table S1). At the sequential infection timepoints, $0.09 \% \pm 0.00 \%, 0.30 \% \pm 0.00 \%, 1.18 \% \pm 0.03 \%$, and $3.71 \% \pm 0.60 \%$, respectively, of the clean reads were mapped against the E. ampelina genome. We detected the expression of 8,003 $(99.32 \%)$ protein-coding genes in all samples based on FPKM (fragments per kilobase of gene per million mapped reads) values $>1$ (Supplementary Tables S2 and S3).
The number of differentially expressed genes (DEGs) shared among the 3-, 4-, and 5-dpi samples also increased over time (Fig. 1E); a total of 37, 293, and 253 upregulated $(P<0.05)$ DEGs and 28, 167, and 143 downregulated DEGs, respectively, were detected compared with the 2-dpi sample (Fig. 1F; Supplementary Table S4).

Distribution and expression analysis of CAZymes and PCWDEs. We compared the CAZyme repertoires of eight Dothideomycetidae species, with an emphasis on plant PCWDEs, to assess the potential of the pathogens to depolymerize cell walls of their plant hosts. A total of 407 CAZymes were identified, collectively, from all six major CAZyme super families in the predicted proteome of E. ampelina (Supplementary Fig. S2; Supplementary Table S5). More were identified in Capnodiales than in Dothideales and E. ampelina. The number of glycosyl transferases in E. ampelina was intermediate between Capnodiales and Dothideales (Supplementary Fig. S3A). We detected the expression of $352(86 \%)$ of the CAZymes during the infection of grape leaves (Supplementary Fig. S3B and C), and significant differences in expression of all these genes were detected at different times after infection with E. ampelina (Supplementary Fig. S3D). We identified 158 PCWDEs in the E. ampelina genome, including nine cellulases, 59 hemicellulases, and 43 pectinases (Supplementary Table S6). More pectinases were found in E. ampelina than in Capnodiales and Dothideales (Supplementary Fig. S4A), and the GH28 and PL9 families were only found in E. ampelina and not in the other eight Dothideomycetidae genomes. A total of $85(77 \%)$ of the PCWDEs from three major PCWDE subfamilies were expressed in infected leaves, and showed significant differences in expression at 3, 4, and 5 dpi (Supplementary Fig. S4B and C), and 21 up- and 18 downregulated PCWDEs were detected in infected grape leaves (Supplementary Fig. S4D).

Distribution and expression of pathogen-host interaction genes and genes involved in secondary metabolism during pathogenesis. The pathogenicity genes were predicted using BLASTP against the Pathogen-Host Interactions database (PHI-base), with 555 protein-coding E. ampelina genes, accounting for $6.8 \%$ of the total predicted genes, associated with virulence and pathogenicity (Supplementary Table S7A). Almost all the genes present in PHI-base $(543$; 98\%) were transcribed in infected grape leaves (Supplementary Table S7B); however, only 29 were differentially expressed $\left(\log _{2}[\right.$ fold change] $>2$ and $P<0.05$ ) between one or more infection stages (Fig. 2A). The predicted proteins corresponding to these genes were annotated, based on sequence homology, as being involved in secondary metabolism, P-type ATPases, transporters, enzymes degrading host physical barriers, metalloproteases, and heat shock proteins.

We identified 20 secondary metabolite biosynthetic clusters in E. ampelina, comprising 255 genes; 149 protein-coding genes $(91 \%)$ related to type 1 nonribosomal peptide synthetase, polyketide synthase (PKS), and terpene were transcribed in infected grape leaves (Supplementary Table S8). Eleven of these were differentially expressed between one or more of the infection stages (Fig. 2B). Three T1PKS gene clusters were predicted and an elsinochrome prefoldin protein in cluster 5 may be involved in the modification of elsinochromes (Supplementary Fig. S5B). Elsinochrome produced by genus Elsino $\ddot{e}$ is a mycotoxin, which is vital to the pathogenic process (Liao and Chung 2008). Finally, to support the idea that E. ampelina secretes toxic metobolities, we tested the effect of culture filtrates of $E$. ampelina on grape leaves and found that culture filtrates of $E$. ampelina caused visible lesions on grape leaves at $24 \mathrm{~h}$ postinoculation (Supplementary Fig. S5A). Taken together, those results suggest that expressed pathogen-host 
interaction genes and toxic metobolities may be involved in the pathogenicity of E. ampelina.

Annotation, expression, and functional analysis of candidate effectors. To search for candidate E. ampelina effectors, we developed an existing bioinformatic pipeline (Supplementary Fig. S1) to predict the effectors of filamentous plant pathogens (Haddadi et al. 2016; Sperschneider et al. 2015). A total of 472 secreted proteins, of which 103 were candidate effector proteins, were predicted in the E. ampelina genome (Supplementary Table S9). Of the 103 candidate effectors in E. ampelina, $39 \%$ had PFAM domains, which is less than the $66 \%$ predicted for all proteins (Supplementary Table S10). We found that 74 $(72 \%)$ of the candidate effectors were expressed in infected grape leaves and 16 were significantly expressed in at least one of the infection stages (Fig. 2C). A total of 27 candidate effectors were down-regulated at 3, 4, and 5 dpi when compared with 2 dpi (Fig. 3A). Twelve candidate effectors were randomly selected from 22 differentially expressed candidate effectors for validation of expression by quantitative real time (qRT)-PCR (Fig. 3B), and the results of this analysis were consistent with the RNA-seq data (Fig. 3C).

Finally, we tested whether the predicted E. ampelina effectors have the capacity to promote or inhibit plant cell death, using an A. tumefaciens transient transformation assay. Effector proteins are often proteins with unknown functions. Nine candidate effectors with high fold changes of expression and unknown function were selected. We first infiltrated A. tumefaciens carrying the potato virus $\mathrm{X}$ (PVX) expression vector with one of the nine different effector genes into Nicotiana benthamiana leaves. After $24 \mathrm{~h}$, these leaves were similarly reinfiltrated with a vector to express cell death-inducing BAX (mouse proapoptotic BAX protein) or hypersensitive response-inducing INF1 (Phytophthora infestans PAMP elicitor infestans 1). Eight effectors were observed to suppress BAX-induced cell death completely, while EaSSP83 had a weak effect, and all nine effectors were able to suppress INF1-induced cell death (Fig. 4; Supplementary Fig. S6). These results suggest that the selected E. ampelina effectors play a role in suppressing host immunity.

\section{Grapevine defense strategies.}

Expression profile of $\mathrm{E}$. ampelina-infected leaves. To investigate the gene expression of grape, we performed RNA-seq profiling of $V$. vinifera 'Red Globe' leaves after infection with E. ampelina $\mathrm{YL}-1$ at 2, 3, 4, and 5 dpi. On average, $91.54 \% \pm$ $1.45 \%$ of the cleaned reads could be mapped against the reference $V$. vinifera PN40024 genome (Supplementary Table S1). The average transcript abundance was $8.84 \% \pm 0.08 \%, 19.42 \%$ $\pm 0.29 \%, 23.59 \% \pm 1.18 \%$, and $13.53 \% \pm 0.28 \%$ at FPKM intervals of $1<$ FPKM $<3,3<$ FPKM $<15,15<$ FPKM $<60$, and FPKM $>60$, respectively (Supplementary Fig. S7A). Correlation coefficients of the transcriptome profiles were 0.99 between each set of biological replicates (Supplementary Fig. S7B). A total of 5,517 DEGs shared among the grape leaves at
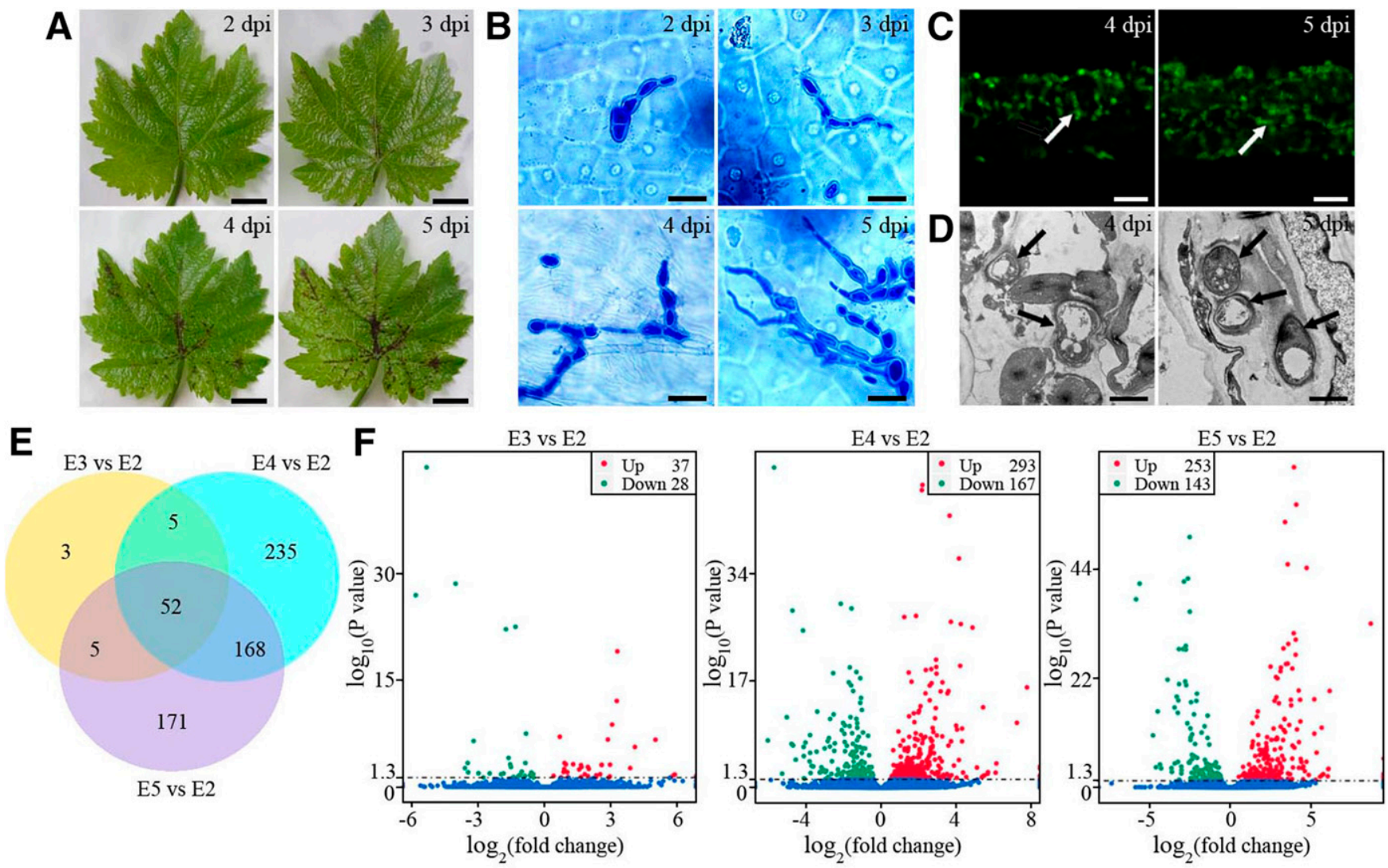

Fig. 1. Genome-wide identification and expression profile of Elsinö̈ ampelina during infection in grape leaves. A, Disease symptoms in E. ampelinainoculated Vitis vinifera 'Red Globe' leaves at 2, 3, 4, and 5 days postinoculation (dpi). Scale bars $=1 \mathrm{~cm}$. B, Conidial development of E. ampelina on leaves of $V$. vinifera 'Red Globe' using trypan blue staining at various days postinoculation. Scale bars $=10 \mu \mathrm{m}$. C, E. ampelina hyphae growth in grape leaves colored with fluorescein isothiocyanate-labeled wheat germ agglutinin at 4 and 5 dpi. White arrows indicate E. ampelina hyphae. Scale bars $=20 \mu \mathrm{m}$. D, Growth of $E$. ampelina hyphae on grape leaves observed using scanning electron microscopy. Black arrows indicate E. ampelina hyphae. Scale bars $=2 \mu$ m. E, Pair-wise comparison of mRNA profiles of the three comparisons and the number of joint differentially expressed genes. E2, E3, E4, and E5 indicate grape leaves after inoculation with E. ampelina at 2, 3, 4, and 5 dpi, respectively. F, Number of differentially expressed $\mathrm{mRNAs}(P<0.05)$ in progressive pairs of the three comparisons. 
3, 4, and 5 dpi (Supplementary Fig. S7C). A total of 3,262, 5,864 , and 7,112 upregulated $(P<0.05)$ DEGs, and 3,180 5,549 , and 7,048 downregulated DEGs in grape leaves after 3, 4, and 5 dpi, compared with 2 dpi (Supplementary Fig. S7D; Supplementary Table S11). Mapped reads ratio of grape genome and correlation coefficients indicated that high-quality transcriptome data were obtained in this study. The number of DEGs were gradually increased during the infection process of E. ampelina.

Gene Ontology $(G O)$ and metabolic pathway analysis in E. ampelina-infected leaves. The DEGs were categorized using GO analysis, which showed that the upregulated DEGs were involved in metabolic process, followed by biosynthetic process, and catabolic processes (Supplementary Fig. S8; Supplementary Table S12). Metabolic pathway analysis showed that phenylpropanoid, stilbene, and lignin are mainly involved due to infection (Supplementary Fig. S9A). Gene enrichment analysis revealed that 38 DEGs were related with the phenylpropanoid pathway. The expression of phenylalanine ammonia lyase, 4-coumarate:CoA ligase, cinnamoyl-CoA reductase, and stilbene synthase were up-regulated, whereas cinnamyl alcohol dehydrogenase $(C A D)$ and caffeoyl CoA $O$ methyltransferase were down-regulated (Supplementary Fig. S9B).

In addition, we explored the gene expression related to terpenoid metabolism, including the mevalonic acid (MEV) and methylerythritol phosphate (MEP) pathways (Supplementary Fig. S10). Transcript abundance for the acetyl-CoA Cacetyltransferase, hydroxymethethylglutaryl-CoA synthase, and diphosphomevalonate decarboxylase genes were increased, whereas phosphomevalonate kinase was decreased within the MEV pathway. For the MEP pathway, four 1-deoxy-Dxylulose-5-phosphate synthases, 2-C-methyl-D-erythritol 2,4cyclodiphosphate synthase, and (E)-4-hydroxy-3-methylbut-2enyldiphosphate genes were up-regulated, whereas 4-(cytidine
A

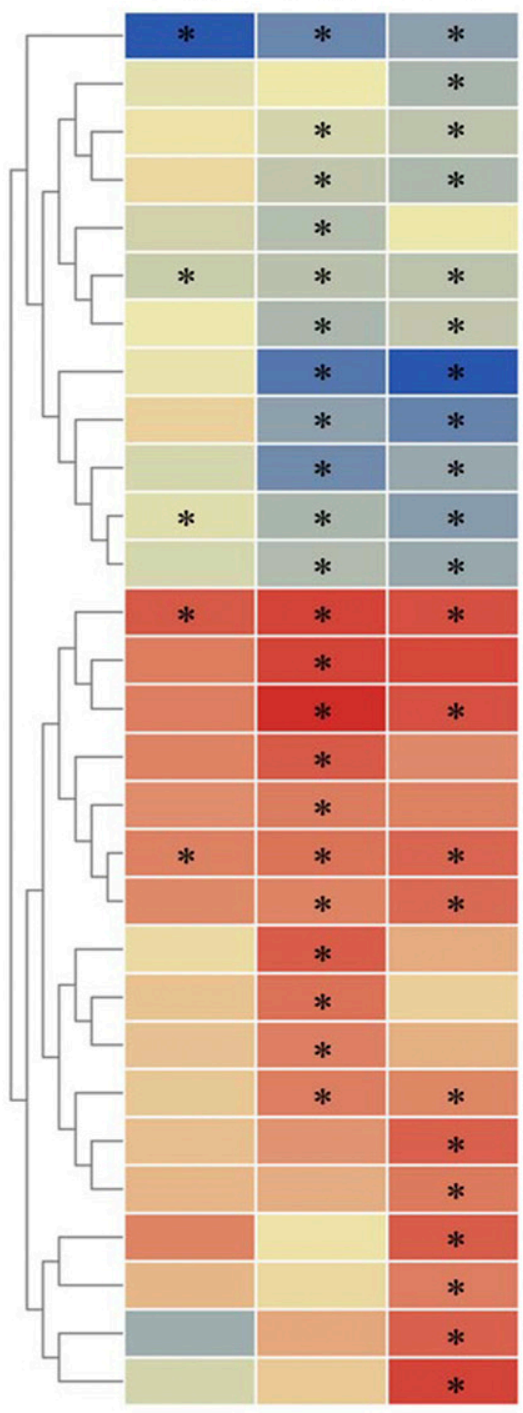

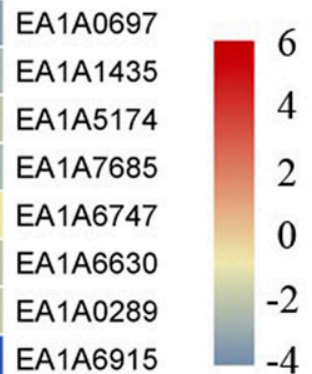

EA1A1904

EA1A2860

EA1A4089

EA1A5927

EA1A3148

EA1A7466

EA1A5032

EA1A5578

EA1A2937

EA1A3152

EA1A2109

EA1A7515

EA1A1186

EA1A6072

EA1A6821

EA1A0864

EA1A2392

EA1A0860

EA1A2505

EA1A0101

EA1A0642
B
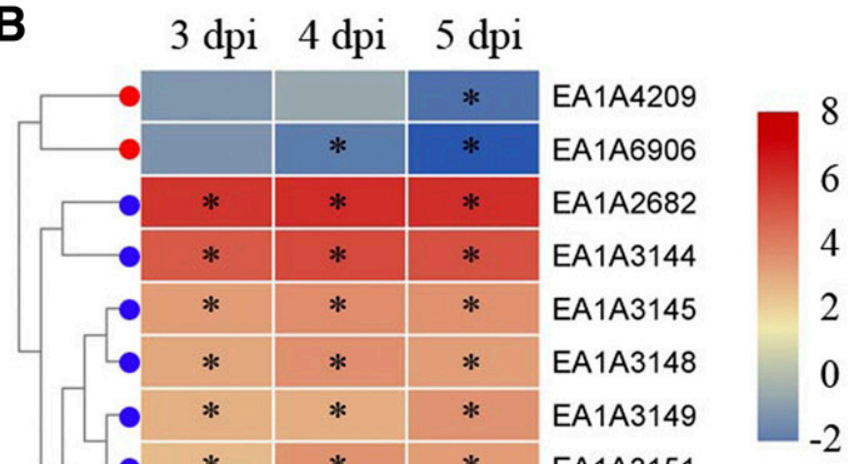

EA1A3151

EA1A0545

EA1A7927

EA1A3152

- NRPS

- Type 1 PKS

- T1PKS-NRPS

C 3 dpi 4 dpi 5 dpi

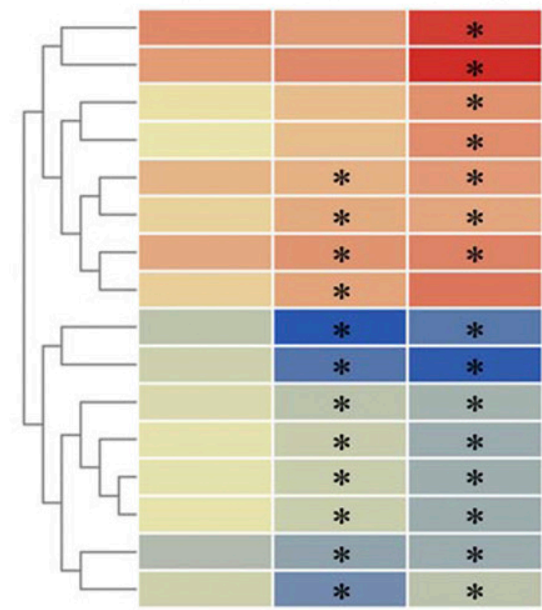

Fig. 2. Expression pattern of pathogen-host interaction (PHI) genes and genes encoding secreted proteins and secondary metabolism during Elsinoë ampelina infection. A, A total of 29 genes involved in PHI, B, 11 genes involved in secondary metabolic processes, and C, 16 candidate effectors were expressed at 3, 4, and 5 days postinoculation (dpi). Blue dots indicate predicted polyketide synthase (PKS) or PKS-like proteins; red dots indicate predicted nonribosomal peptide synthetase (NRPS) and NRPS-like proteins; black dots indicate predicted PKS-NRPS proteins. Each column represents the fold change in transcript levels in grape leaves at the indicated times, relative to the levels at 2 dpi. Asterisks indicate a significant difference (false discovery rate $<0.05$ ) based on RNAseq data analysis. The vertical dimension represents genes that exhibited changes in transcript $\operatorname{level}_{\text {( }} \log _{2}[$ fold- change] $>2$ and $P<0.05$ ). The color scale indicates transcript abundance with red indicating an increase in relative transcript abundance and blue a decrease in relative transcript abundance. 
5'-diphospho)-2-C-methyl-D-erythritol kinase was downregulated. Taken together, the expression of genes related to stilbene and terpenoid synthesis were up-regulated in susceptible $V$. vinifera 'Red Globe'.

Plant cell-wall degradation and reactive oxygen species (ROS) scavenging in response to infection with E. ampelina. From histological studies over different time scales after infection, it is clear that the cell walls of grape leaves retained structural integrity at $2 \mathrm{dpi}$, and, after this, cell walls of mesophyll cells progressively collapsed from $3 \mathrm{dpi}$, using periodic acid silver hexamine staining and transmission electron microscopy, respectively (Supplementary Fig. S11A and B). Transcriptome analysis revealed that 23 DEGs related to plant cell-wall degrading were up-regulated, such as pectinesterases and parts of beta-glucosidases. In contrast, most of the polygalacturonases were down-regulated (Supplementary Fig. S11C). The ROS levels gradually increased over time after inoculation, using diaminobenzidine (DAB) staining (Supplementary Fig. S12A). A total of 22 DEGs were involved in antioxidation, peroxidase (POD)-upregulated during infection
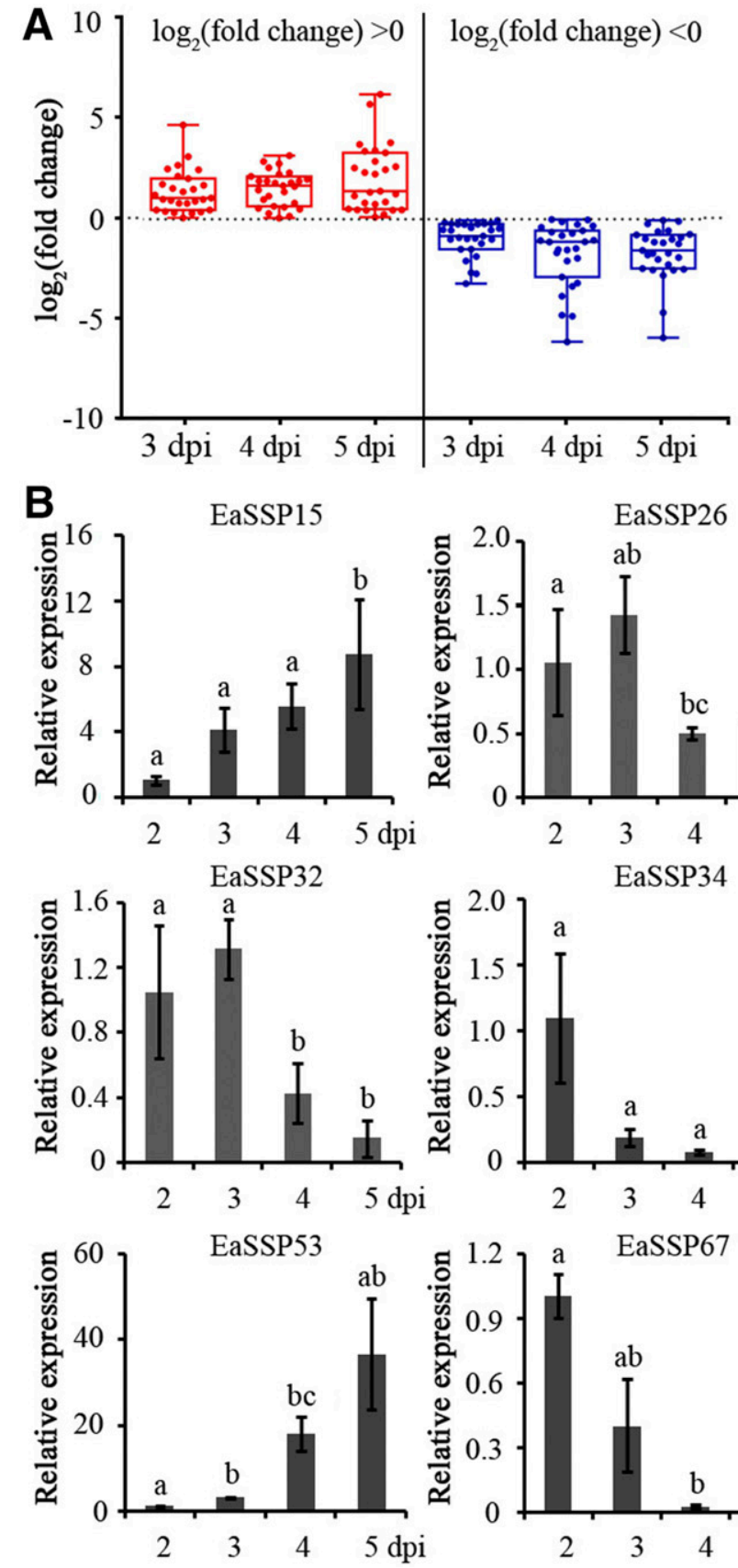

Days after inoculation

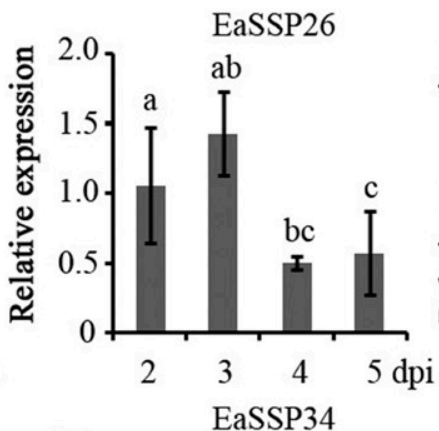

C

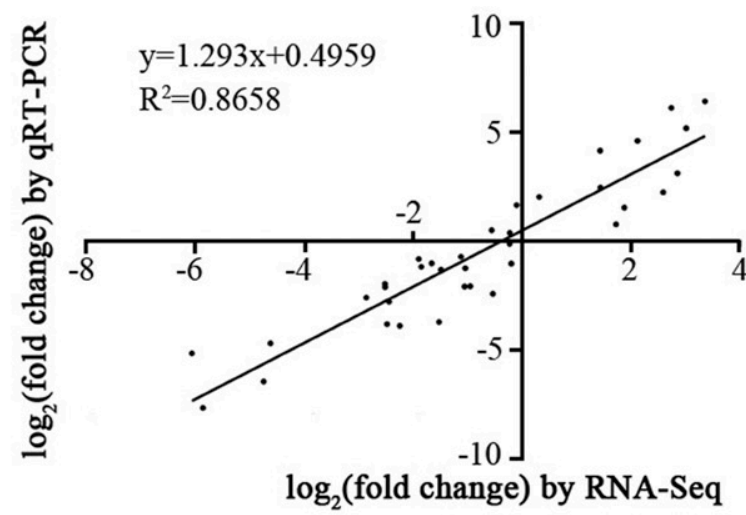

EaSSP29
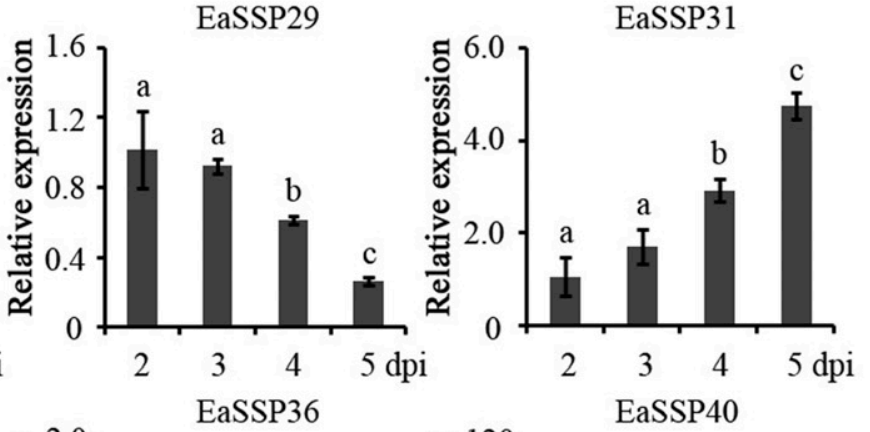
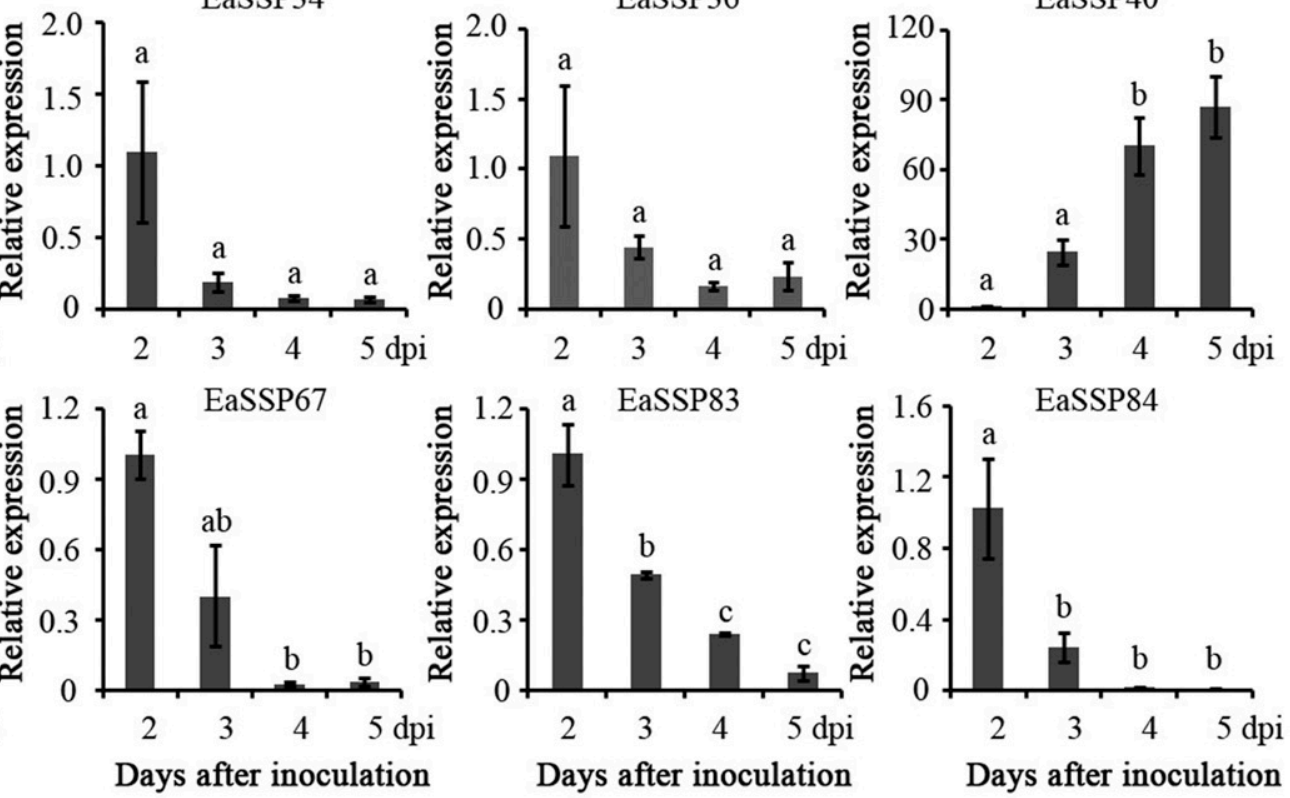

Fig. 3. The expression of Elsinö ampelina effectors associated with infection. A, Box plot of the expression of candidate effectors based on the log ${ }_{2}$-fold change in grape leaves at 3,4 , and 5 days postinoculation (dpi). Red, $\log _{2}$-fold change $>0(n=27)$; blue, $\log _{2}$-fold change $<0(n=27)$. $P$ values were calculated using a two-sample Student's $t$ test. B, Twelve candidate effectors were selected for validation of the RNA-seq data based on quantitative real time (qRT)-PCR. Data and relative values are the means standard deviation of three biological replicates. Different letters above the bars indicate statistically significant differences $(P<0.05)$ according to one-way analysis of variance followed by Tukey or Games-Howell post hoc tests. C, Correlation between RNA-seq and qRT-PCR data. The Pearson's correlation coefficient between relative expression levels is shown. 
of the E. ampelina, while DEGs related to catalase (CAT) and superoxide dismutase $(S O D)$ decreased. Moreover, of three DEGs related to glutathione peroxidase $(G S H)$, two were upregulated and the other one was down-regulated at the three infection stages (Supplementary Fig. S12B). Those results showed that pectin degrading and ROS scavenging by POD and GSH are the key characteristics of grape leaves responding to E. ampelina.

Differential expression of transcription factors and hormone signaling. Transcription factors (TFs) are known to be induced by pathogens and likely play important roles in plant defense regulatory networks. We investigated the expression of TFs, and a total of 468 DEGs were identified and were assigned to 61 TF families (Supplementary Table S13). The greatest share of the DEGs related to TFs were members of the AP2/EREBP family (10.25\%), followed by the MYB family (10.04\%), the WRKY family $(5.56 \%)$, the basic helix-loop-helix proteins (bHLH) family (5.34\%), and the NAC family (5.13\%). Among them, 29 ethylene (ET)-responsive factors (ERFs) (Zhu et al. 2019), 25 WRKYs (Guo et al. 2014), 16 NACs (NAM, ATAF1/2, and CUC2) (Wang et al. 2013), 14 bHLHs (Gao et al. 2019), and five squamosa promoter-binding proteins (SBPs) (Hou et al. 2013) were identified to be involved in plant defense. Most of the DEGs encoding SBPs were down-regulated, while those related to WRKYs were up-regulated, from 3 to 5 dpi. In addition, ERFs were predominantly up-regulated at $4 \mathrm{dpi}$ in response to infection with $E$. ampelina (Supplementary Fig. S13).

The expression of genes involved in the biosynthesis of jasmonates (JA), salicylic acid (SA), and ET were significantly altered in response to infection with E. ampelina. JA is a signaling molecule derived from $\alpha$-linolenic acid (Supplementary Fig. S14A) and plays an important role against pathogens (Guo et al. 2018). In addition to allene oxide cyclase, 13 DEGs associated with the JA biosynthetic genes were up-regulated (Supplementary Fig. S14B). Similarly, the expression of most genes related to ET biosynthesis were up-regulated in response to E. ampelina. PR1 and NPR1 were up-regulated, while isochorismate synthase related to SA biosynthesis was downregulated (Supplementary Fig. S14C). Our results suggest that JA and ET may be involved in the modulation of defense responses to E. ampelina at later infection stages.
E. ampelina triggers plant defense responses during the interaction with grape. A characteristic transcriptome feature of grape anthracnose is upregulation of a gene-related defense system in grape leaves (Supplementary Table S14). For example, 41 receptor-like kinases were up-regulated in infected grape leaves, including 28 leucine-rich repeat (LRR) receptors and 13 lectin receptors (Fig. 5A and B). A total of 56 DEGs related to LRR receptors were down-regulated. For lectin receptors, 21 DEGs were down-regulated in infected grape leaves. Additionally, 24 genes encoding antimicrobial proteins and glutathione- $S$-transferase that play roles in disease resistance were up-regulated (Fig. 5C and D).

\section{DISCUSSION}

Grape anthracnose caused by Elsinoë ampelina is one of the most destructive diseases of grapevines worldwide (Braga et al. 2020). This disease causes early defoliation and berry drop and berry yield and quality losses (Magarey et al. 1993; Thind et al. 2004). So far, there is no information about the molecular processes underlying the grape-E. ampelina interaction. Dual RNA-seq has facilitated simultaneous detection of gene expression for pathogens and host plants in various pathosystems (Tao et al. 2020). Availability of the reference genomes of grape and E. ampelina made it possible to investigate the transcripts expressed in infected grape leaves. In this study, we used a simultaneous transcriptomic profiling approach to monitor fungal genes related to pathogenesis and grape genes related to defense.

E. ampelina is a hemibiotroph during the foliar infection stage, but little molecular evidence is available to support and define the biotrophic and necrotrophic. It has been reported that plants activate the SA pathway, at early stages, and the ET/JA pathways, at later stages, after infection by hemibiotrophic pathogens (Glazebrook 2005). Our results showed that isochorismate synthase was down-regulated and most of the JA biosynthetic genes were up-regulated during the foliar infection of E. ampelina. Genes encoding necrosis- and ET-inducing-like proteins (NLP) are usually highly expressed especially toward entering of the necrotrophic stage or during the necrotrophic stage (Feng et al. 2014). The expression patterns of NLPs are
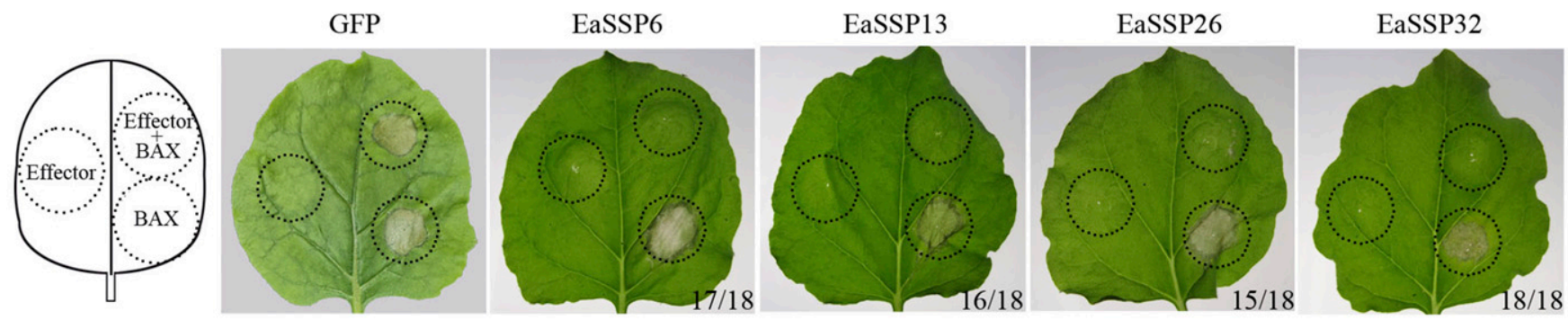

EaSSP36 EaSSP62

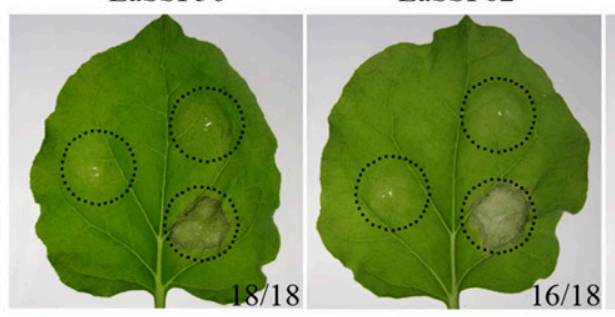

EaSSP67

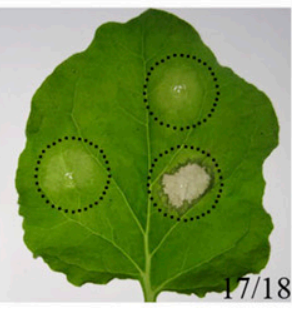

EaSSP83

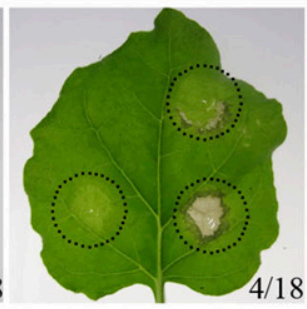

EaSSP86

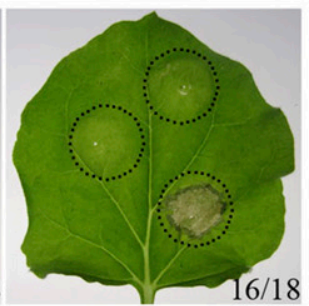

Fig. 4. Nine putative Elsinoë ampelina effectors suppressed cell death triggered by BAX (mouse proapoptotic BAX protein). Agrobacterium tumefaciens infiltration sites in Nicotiana benthamiana leaves expressing nine effectors were challenged with A. tumefaciens expressing the BAX elicitin. An A. tumefaciens strain carrying potato virus X green fluorescent protein (PVX-GFP) was used as a control. Representative cell death symptoms were photographed at 6 days after PVX-BAX infiltration. The left sides of the leaves were infiltrated with PVX-effectors and the right sides with PVX-BAX and the effector gene constructs. Ratios indicate the proportion of infiltrated sites that suppressed the cell-death phenotype. 
well-known markers for the lifestyle of fungal pathogens (Haddadi et al. 2016). Other clear evidence was that we identified a NLP protein (gene ID EA1A0169) based on genome sequence, $53.6 \%$ sequence identity with $M g N L P$ from Zymoseptoria tritici (PHI-base accession Mycgr3g88451), but there is no difference in the expression of this genes during its infection in grape leaves. Additionally, histopathological observation of E. ampelina showed that there was no obvious appressorium formation related to hemibiotrophic infection (Braga et al. 2019; Z. Li et al. 2019b). E. rosarum, a species of Elsino $\ddot{e}$, has been reported as a hemibiotrophic ascomycete causing spot anthracnose on roses (Bagsic et al. 2016). Overall, E. ampelina may be a hemibiotrophic ascomycete in grape.

There are fewer CAZymes and major CAZyme superfamilies in E. ampelina than in Capnodiales and Dothideales. However, more pectinases were found in E. ampelina than in Capnodiales and Dothideales, and the GH28, GH88, and PL9 families involved in degrading pectin were upregulated during infection. GH88 and PL9 genes were only found in E. ampelina and not in the other eight Dothideomycetidae genomes investigated here (Supplementary Table S5). Based on these differences, we propose that E. ampelina evolved specific adaptations for nutrient utilization and effective exploitation of the grape host.
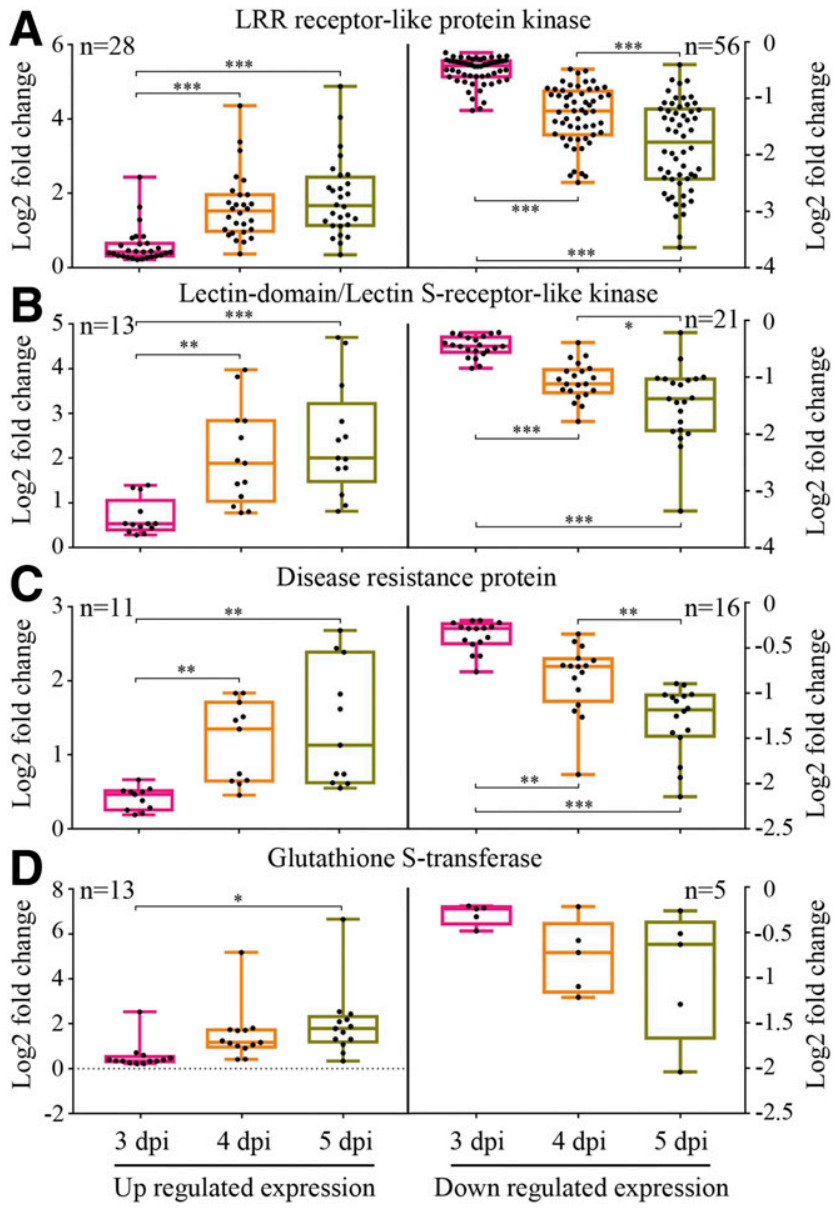

Fig. 5. Resistance-related differentially expressed genes (DEGs) in the Elsinoë ampelina-infected leaves of Vitis vinifera 'Red Globe'. A, Leucinerich repeat receptor-like serine/threonine-protein kinase, B, lectindomain/lectin S-receptor-like kinase, $\mathbf{C}$, disease resistance protein, and $\mathbf{D}$, glutathione S-transferase. Asterisks above the bars indicate significant differences according to one-way analysis of variance followed by Tukey or Games-Howell post hoc tests (one asterisk (*) indicates $P<0.05$, two (**) $P<0.01$, and three (***) $P<0.001$ ).
Fungal metabolites can act as important virulence factors during infection of plant cells (Möbius and Hertweck 2009), and indeed, we observed that application of extracts from culture filtrates of E. ampelina to grape leaves caused obvious lesions (Supplementary Fig. S5). Elsinoë species are known to produce elsinochromes, which, under light, produce ROS with cellular toxicity (Liao and Chung 2008). We identified a type 1 PKS gene cluster involved in the biosynthesis and modification of elsinochromes; however, most genes in this cluster were downregulated during infection, suggesting that elsinochromes might play a role in early infection.

In planta expression profiles indicated that many CAZymes, PHI-base genes and secreted proteins were upregulated during infection. Fungal effectors are known key pathogenicity factors that regulate plant immunity and effect disease development during plant-pathogen interactions (Lo Presti et al. 2015; Rovenich et al. 2014). Most are small, secreted proteins lacking homology to functionally characterized proteins (Stergiopoulos and de Wit 2009; Valent and Khang 2010). We found 103 small candidate effectors from 472 putative secreted proteins, of which 74 were expressed in infected grapevine leaves. The primary function of effectors secreted by fungi, oomycetes, and nematodes is thought to be suppression of plant innate immunity. In this study, eight and nine effectors suppressed cell death induced by BAX and INF1, respectively, in $N$. benthamiana leaves, suggesting that they recognize the same protein in $N$. benthamiana and grapevine (Liu et al. 2018) to suppress plant innate immunity. In particular, nine effector candidates were selected based on their up- or down-regulated expression during infection and their status as proteins of unknown function (Supplementary Table S9). Combined with the results of the transient expression assays in $N$. benthamiana, we suggest that these effectors contribute to shaping the interaction of E. ampelina with grapevine.

It is well-known that phenylpropanoid, stilbene, and terpenoid compounds associate with grape defense against pathogens (Dixon et al. 2002; Fröbel et al. 2019; Liu et al. 2019). RNA-seq analysis also showed that expression of those metabolic synthesis genes were up-regulated (Supplementary Fig. S8). Interestingly, the CADs, a key enzyme in lignin synthesis, were down-regulated during the E. ampelina infection. Another study reported similar results, in that CADs were downregulated at $1 \mathrm{dpi}$ in wheat after Zymoseptoria tritici infection (Rudd et al. 2015). However, most peroxidase genes, involved in lignin biosynthesis, were up-regulated (Supplementary Fig. S12). It is possible that CADs were the targets of fungal effectors, such as Avr3a-like effectors from Phytophthora infestans, and of host protein modified by Rhizoctonia solani, such as ZMFBL41 from maize (N. Li et al. 2019; T. Li et al. 2019), and lost the lignin biosynthetic activity.

Another important aspect of plant defense responses is the accumulation of ROS, which is observed at later stages of E. ampelina in this study. Biotrophic and hemibiotrophic fungi depend on the prevention of ROS, whereas necrotrophic fungi seem to exploit ROS during the infection process (Heller and Tudzynski 2011), suggesting that E. ampelina may use a hemibiotrophic infection. However, further studies are necessary to confirm the trophic relationships between grape and $E$. ampelina. In this study, most of the antioxidant enzyme genes (including $C A T$ and $S O D$ ) were down-regulated under oxidative stress conditions. This result is consistent with a previous study in tomato-Phytophthora infestans interaction (Cai et al. 2013). This might be due to the ROS bursts that are suppressed by pathogen effectors (Jwa and Hwang 2017). It has been shown that the effector Pep1 of Ustilago maydis inhibits ROS production in maize (Hemetsberger et al. 2012) and the effector PstGSRE1 defeats ROS-induced defense in wheat (Qi 
et al. 2019). Although ROS repression in the grape-E. ampelina interaction is not yet known, it would be interesting to investigate the relationship between ROS production and effectors of E. ampelina.

One of the plant defense responses to pathogen is their regulation by phytohormones such as SA, JA, and ET (van de Mortel et al. 2012). In this study, the analysis of the expression profile of plant hormone-related genes showed a notable lag in JA response through upregulated expression of JA biosynthetic genes at the later stages and SA biosynthetic genes at the earlier stages of infection (Supplementary Fig. S14). PR1 and NPR1 were induced, suggesting that the SA pathways were activated. Our data are consistent with previous reports for expression of genes related to both SA and JA pathways from RNA-seq data (Haddadi et al. 2016; Zuluaga et al. 2016). For ET, the most biosynthetic genes and ERF transcription factors were induced at later stages. Those results suggested that grapes challenged by E. ampelina induced the SA pathway followed by JA and ET pathways.

The growth-defense conflict is a well-known phenomenon in plants. Although some terms obtained by GO enrichment analysis were different at the three timepoints, most of them were related to metabolic processes in our study. The change of phenylpropanoid, stilbene, and terpenoid compounds involved grape defense against pathogens. Several grape receptors were up-regulated in response to $E$. ampelina, including the LRR receptor and lectin receptors. However, this defense is costly and is often accompanied by significant growth and yield inhibition (Deng et al. 2017; Yang et al. 2012). Additionally, defense response is more intense in susceptible grapes than resistant grapes. Fung et al. (2008) reported that over-reprogramming of the transcriptome was activated in susceptible $V$. vinifera instead of resistant $V$. aestivalis after infection with powdery mildew fungus. In this study, susceptible $V$. vinifera 'Red Globe' did not effectively prevent $E$. ampelina infection and symptom development, although the host activated multiple defense responses against E. ampelina, including synthesis of metabolites, regulation by phytohormones, and expression of defense-related genes.

In conclusion, transcriptome analysis revealed the expression pattern of genes involved in virulence, such as coding CAZymes, secondary metabolite clusters, effectors, and PHI-base genes. Functional studies indicate that putative effectors play important roles in virulence and provide a reference for developing effective disease management strategies of grape anthracnose. Hormone signaling, defense regulators, and production of phenylpropanoids, stilbenes, and terpenoids may be required for resistance against $E$. ampelina (Fig. 6). These results are also pivotal to future studies that choose the candidate genes and identify the gene function from our dataset. Overall, the transcriptome interaction analysis of E. ampelina-grape provided here should help elucidate the molecular mechanisms underlying pathogenesis of E. ampelina and the host-response mechanism to E. ampelina infection.

\section{MATERIALS AND METHODS}

\section{Fungal strain and grape material.}

Elsinö ampelina YL-1 was isolated from three-year-old diseased leaves of Vitis vinifera 'Red Globe' and was grown on potato dextrose agar (PDA) media at $25^{\circ} \mathrm{C}$ in constant darkness, as previously described ( $\mathrm{Li}$ et al. 2018). Four-year-old $V$. vinifera 'Red Globe' trees were asexually propagated and spaced from 2 to $4 \mathrm{~m}$ apart in the germplasm nursery of Northwest A\&F University, Shaanxi, China.

\section{Grapevine infection.}

E. ampelina conidia were harvested with distilled water from 25-day-old cultures grown in PDA bottles, and the concentration was adjusted to $2 \times 10^{6}$ conidia per milliliter, using a hemocytometer and the method described by $\mathrm{Z}$. Li et al. (2019b). The third leaves of five-year-old $V$. vinifera 'Red Globe' were selected randomly from the top of the shoot and were sprayed in the field with the conidial suspension until runoff. The inoculated leaves were enclosed in individual plastic bags. Leaves of infected grapevines were collected at 2, 3, 4, and $5 \mathrm{dpi}$ and were immediately frozen in liquid nitrogen. A total of 10 compound leaves were randomly chosen from five grape plants at different timepoints and each assay was repeated three times to provide biological replicates.

\section{Microscopy observations.}

Conidial germination of E. ampelina was observed with trypan blue staining according to the method of $\mathrm{Z}$. Li et al. (2019b). E. ampelina development was observed using transmission electron microscopy (SU8010, Hitachi, Tokyo) and fluorescein isothiocyanate-labeled wheat germ agglutinin (WGA-FITC) (Sigma-Aldrich) staining, as previously described (Z. Li et al. 2019b). Inoculated grape leaves were incubated with $20 \mu \mathrm{g}$ WGA-FITC per milliliter (Sigma-Aldrich) for $12 \mathrm{~h}$ in the dark and were observed with an Olympus BX-53 microscope (Olympus, Tokyo) under blue light excitation. DAB staining was carried out as previously described (Wan et al. 2015). Whole infected leaves were directly stained in a DAB solution $(1 \mathrm{mg} / \mathrm{ml}$, with $\mathrm{HCl}$ acidifying to $\mathrm{pH} \mathrm{3.8)}$ for $8 \mathrm{~h}$ under light, were cleared at $80^{\circ} \mathrm{C}$ in $80 \%$ ethanol for $2 \mathrm{~h}$, and were then placed in $10 \%$ glycerol for observation. Nine pieces from three inoculated grape leaves were observed each time. Each assay was performed three times.

Periodic acid silver hexamine (PASH) was used to observe the cell wall of grape leaves from 2 to 5 dpi. For PASH, infected grape leaf pieces $(0.5 \times 0.5 \mathrm{~cm})$ were fixed in FAA solution ( $90 \mathrm{ml}$ of $70 \%$ ethanol, $5 \mathrm{ml}$ of formalin, and $5 \mathrm{ml}$ of acetic acid), were dehydrated in an ethanol series, and were embedded in paraffin (Tanaka et al. 2017). Sections were oxidized in $1 \%$ periodic acid for $10 \mathrm{~min}$ and were stained in silver hexamine solution at $60^{\circ} \mathrm{C}$ for $30 \mathrm{~min}$, using the method described by Heath and Heath (1971), were washed using distilled water, and were then observed with BX-53 microscope (Olympus).

\section{RNA-seq analysis.}

To investigate E. ampelina gene expression in grape leaves, total RNA was extracted from inoculated grape leaves using Trizol reagent (Invitrogen, Carlsbad, CA, U.S.A.) according to manufacturer protocol. RNA degradation and contamination was assessed by $1 \%$ agarose gel electrophoresis, and purity and concentration were determined using a Nanodrop (Thermo Scientific, Waltham, MA, U.S.A.) and a Qubit 2.0 fluorometer (Life Technologies, Carlsbad, CA, U.S.A.), respectively. cDNA was synthesized using the PrimeScript RT Reagent Kit with the gDNA Eraser (Takara, Tokyo). Transcriptome sequences were obtained using an Illumina HiSeq 2500 at the Beijing Novogene Bioinformatics Technology Co., Ltd (Beijing). Highquality reads were aligned against the E. ampelina YL-1 genome and $V$. vinifera reference genome $(12 \times$ PN40024), respectively. Gene expression was normalized by calculating the target FPKM (Trapnell et al. 2012). DEG analysis was performed using the DESeq2 v1.10.1 software using the Benjamini and Hochberg approach (Love et al. 2014). Transcripts with a corrected $P$ value $<0.05$ (false discovery rate $=0.05$ ) and a fold change $>2$ were considered to be significant DEGs relative to the expression levels at $2 \mathrm{dpi}$. The DEGs were then performed 
with GO enrichment, with the threshold of $P$ value $<0.05$, using GOSeq v. 2.12 (Joung et al. 2009). Venn diagram and hierarchical clustering were used to illustrate the differential gene expression patterns between different groups. Heatmaps were produced using TBtools v0.664 software (Chen et al. 2018).

\section{qRT-PCR analysis.}

qRT-PCR was performed to validate the RNA-seq transcriptome data, with 12 predicted E. ampelina effectors as the target genes. The primers listed in Supplementary Table S15 were used. The EF1- $\alpha$ (GenBank accession number KY684935.1) gene was used to normalize gene expression. The PCR system and procedures were as described by Wang et al. (2016). Relative gene expression levels were calculated using the $2^{-\Delta \Delta C T}$ method (Livak and Schmittgen 2001).

\section{Functional annotations of CAZymes, pathogen-host interactions genes and genes involved in secondary metabolism.}

The genome of E. ampelina in this study has been deposited at GenBank under the accession number SMYM00000000 ( $\mathrm{Li}$ et al. 2020). CAZymes were predicted by the CAZymes database with a BLAST e-value cut-off of 1e-5. Pathogen-host interaction genes were annotated using PHI-base (Urban et al. 2017). We analyzed the secondary metabolism gene clusters using antiSMASH v. 2.02 (Blin et al. 2017). PFAM annotation of each gene was performed based on the Pfam database (Bateman et al. 2004).

\section{Secreted proteins and potential effector analysis.}

For secretome annotations, the SignalP 4.0 (Petersen et al. 2011), TMHMM v. 2.0 (Emanuelsson et al. 2000) and kohgpi1.5 programs (GPI-SOM database) were used to predict the presence of signal peptides, transmembrane (TM) domains and glycosylphosphatidylinositol (GPI)-anchor signals, respectively. Briefly, proteins with a signal peptide were predicted by SignalP 4.1 (D-score $>0.5$ ), whereas those with no TM domains and no GPI-anchor signal were considered as candidate secreted proteins. An effector was identified as a sequence with $\leq 300$ amino acids and with four or more cysteine residues (Mirzadi Gohari et al. 2015). The prediction was re- examined by TargetP v. 2.0 (Emanuelsson et al. 2000) and WoLF PSORT (Horton et al. 2007) to determine the predicted cellular localization of each protein. Nuclear localization was predicted with the NLStradamus program (Nguyen Ba et al. 2009).

Pathogenicity analysis of secreted metabolites.

Following the previously published methods of $\mathrm{Z}$. Li et al. (2019a), E. ampelina isolate YL-1 conidia were inoculated into a $250-\mathrm{ml}$ flask containing $100 \mathrm{ml}$ of Czapek liquid medium. The cultures were then incubated at $25^{\circ} \mathrm{C}$ in a water bath shaker for 15 days. Cultures were filtered to remove mycelia, were centrifuged at $4,000 \times g$ for $15 \mathrm{~min}$, and were extracted three times with half volumes of ethyl acetate. The solvent fractions were evaporated at $45^{\circ} \mathrm{C}$. The resulting dry fraction was dissolved in sterile distilled water and was adjusted to different concentrations $(100,200,400$, and $800 \mathrm{ng} / \mathrm{ml})$. A 5- $\mu 1$ solution was inoculated on $V$. vinifera 'Red Globe' leaves. Sterile water served as the control.

\section{Agrobacterium-mediated transient expression in N. benthamiana.}

The coding sequence of nine putative effectors, without the predicted signal peptides, were amplified and individually inserted into the PVX vector (Wang et al. 2011). The amplification primers are listed in Supplementary Table S15. Constructs were introduced into A. tumefaciens GV3101 by electroporation (Dong et al. 2015), and PVX-effector transformants were grown in Luria Bertani medium supplemented with kanamycin $(50 \mu \mathrm{g} / \mathrm{ml})$, were pelleted by centrifugation at $2,500 \times g$ for $15 \mathrm{~min}$, and were then resuspended in MES buffer (10 mM magnesium chloride, $10 \mathrm{mM}$ MES [pH = 5.7], $200 \mu \mathrm{M}$ acetosyringone) and were grown in the dark for $4 \mathrm{~h}$ at $28^{\circ} \mathrm{C}$ before infiltration. A. tumefaciens GV3101 cultures carrying one of the different effector vectors were infiltrated into fully expanded $N$. benthamiana leaves using a needleless syringe, as described by Zhang et al. (2014). PVX green fluorescent protein served as a control. For coexpression experiments, leaves were infiltrated with the effectors $24 \mathrm{~h}$ prior to infiltration with PVX BAX and INF1. Cell death symptoms were evaluated and photographed at 6 dpi.

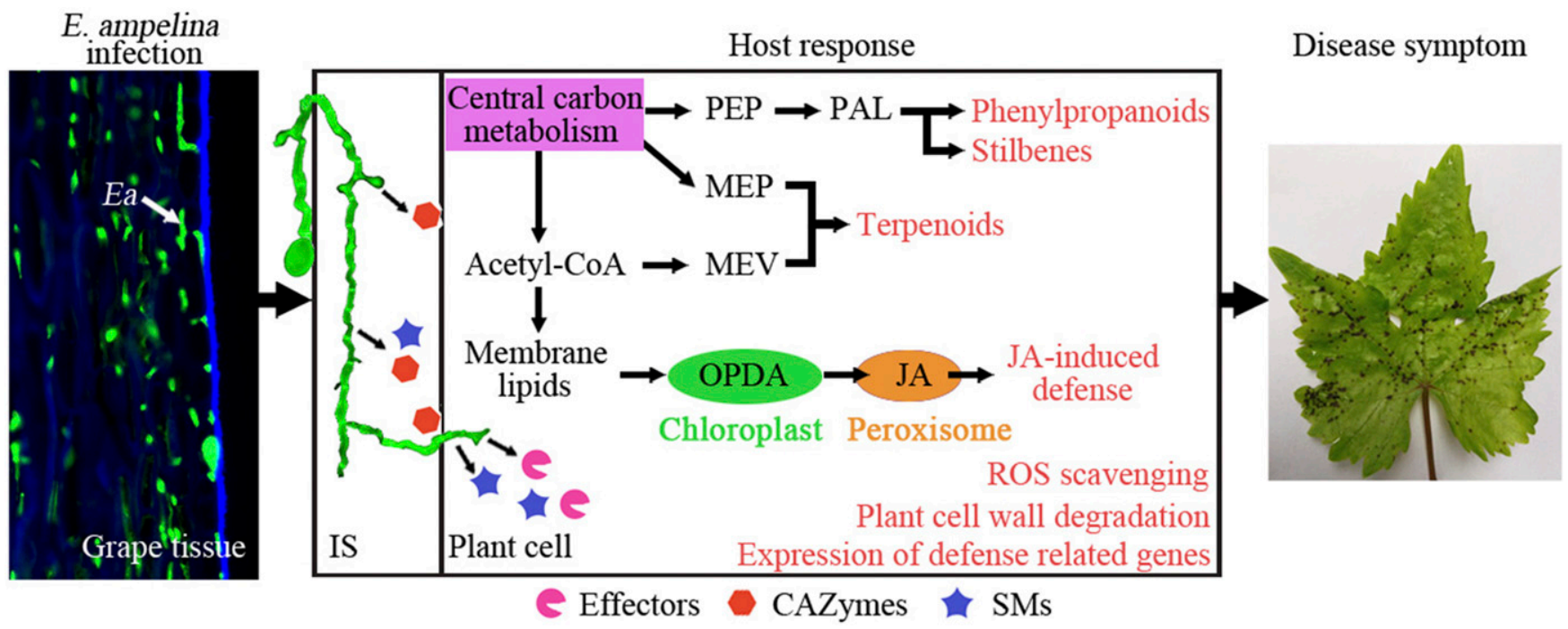

Fig. 6. Overview for Elsinö̈ ampelina-induced host responses in grape leaves. Defense-associated compounds from carbon metabolism pathways in grape include phenylpropanoids, stilbenes, terpenoids, and jasmonates. In addition to the changes of metabolites, reactive oxygen species (ROS) scavenging, plant cell-wall degradation, and expression of defense-related genes also contribute to the host response (pink) in this study. CAZymes $=$ carbohydrate-active enzymes, Ea = E. ampelina, IS = intercellular space, JA = jasmonates, MEP = methylerythritol 4-phosphate, OPDA = 12-oxocis-10,15-phytodienoic acid, PAL $=$ phenylalanine ammonia lyase, $\mathrm{PEP}=$ phosphoenolpyruvate, $\mathrm{MEV}=$ mevalonate, and SMs $=$ secondary metabolites . 


\section{Statistical analysis.}

Significant difference was determined using a one-way analysis of variance followed by Tukey posthoc test, when a normal distribution was observed, and Games-Howell posthoc test, when a nonnormal distribution was observed, using SPSS version 26.0 (SPSS, Chicago).

\section{Data availability.}

The YL-1 genome sequence data has been deposited at the DDBJ/ENA/GenBank database under the accession number SMYM00000000 (BioProject: PRJNA526997, BioSample: SAMN11125508). Raw RNA-Seq data have been deposited in the National Center for Biotechnology Information Sequence Read Archive under the accession number PRJNA526817.

\section{ACKNOWLEDGMENTS}

We thank editors of Molecular Plant-Microbe Interactions and the anonymous reviewers for thoughtful comments on a draft. We are grateful to Y. Xu and G. Liu at Northwest A\&F University for providing help with Agrobacterium-mediated transient assays.

\section{AUTHOR-RECOMMENDED INTERNET RESOURCE}

GPI-SOM database: http://gpi.unibe.ch/

\section{LITERATURE CITED}

Agudelo-Romero, P., Erban, A., Rego, C., Carbonell-Bejerano, P., Nascimento, T., Sousa, L., Martínez-Zapater, J. M., Kopka, J., and Fortes, A. M. 2015. Transcriptome and metabolome reprogramming in Vitis vinifera cv. Trincadeira berries upon infection with Botrytis cinerea. J. Exp. Bot. 66:1769-1785.

Bagsic, I., Linde, M., and Debener, T. 2016. Genetic diversity and pathogenicity of Sphaceloma rosarum (teleomorph Elsinoë rosarum) causing spot anthracnose on roses. Plant Pathol. 65:978-986.

Barros, L. B., Biasi, L. A., Carisse, O., and May De Mio, L. L. 2015. Incidence of grape anthracnose on different Vitis labrusca and hybrid cultivars and rootstocks combination under humid subtropical climate. Australas. Plant Pathol. 44:397-403.

Bateman, A., Coin, L., Durbin, R., Finn, R. D., Hollich, V., Griffiths-Jones, S., Khanna, A., Marshall, M., Moxon, S., Sonnhammer, E. L. L., Studholme, D. J., Yeats, C., and Eddy, S. R. 2004. The Pfam protein families database. Nucleic Acids Res. 32:D138-D141.

Blin, K., Medema, M. H., Kottmann, R., Lee, S. Y., and Weber, T. 2017. The antiSMASH database, a comprehensive database of microbial secondary metabolite biosynthetic gene clusters. Nucleic Acids Res. 45:D555-D559.

Braga, Z. V., dos Santos, R. F., Amorim, L., and Appezzato-da-Glória, B. 2020. Histopathological evidence of concomitant sexual and asexual reproduction of Elsinö̈ ampelina in grapevine under subtropical climate. Physiol. Mol. Plant Pathol. 111:101517.

Braga, Z. V., Santos, R. F., Amorim, L., and Appezzato-da-Glória, B. 2019. Histopathology of infection and colonisation of Elsinoë ampelina on grapevine leaves. Eur. J. Plant Pathol. 154:1009-1019.

Brilli, M., Asquini, E., Moser, M., Bianchedi, P. L., Perazzolli, M., and SiAmmour, A. 2018. A multi-omics study of the grapevine-downy mildew (Plasmopara viticola) pathosystem unveils a complex protein codingand noncoding-based arms race during infection. Sci. Rep. 8:757.

Cai, G., Restrepo, S., Myers, K., Zuluaga, P., Danies, G., Smart, C., and Fry, W. 2013. Gene profiling in partially resistant and susceptible nearisogenic tomatoes in response to late blight in the field. Mol. Plant Pathol. 14:171-184.

Chang, T. C., Salvucci, A., Crous, P. W., and Stergiopoulos, I. 2016. Comparative genomics of the Sigatoka disease complex on banana suggests a link between parallel evolutionary changes in Pseudocercospora fijiensis and Pseudocercospora eumusae and increased virulence on the banana host. PLoS Genet. 12:e1005904.

Chen, C., Xia, R., Chen, H., and He, Y. 2018. TBtools, a toolkit for biologists integrating various biological data handling tools with a userfriendly interface. Mol. Plant 13:1194-1202.

de Wit, P. J., van der Burgt, A., Ökmen, B., Stergiopoulos, I., Abd-Elsalam, K. A., Aerts, A. L., Bahkali, A. H., Beenen, H. G., Chettri, P., Cox, M. P., Datema, E., de Vries, R. P., Dhillon, B., Ganley, A. R., Griffiths, S. A., Guo, Y., Hamelin, R. C., Henrissat, B., Kabir, M. S., Jashni, M. K.,
Kema, G., Klaubauf, S., Lapidus, A., Levasseur, A., Lindquist, E., Mehrabi, R., Ohm, R. A., Owen, T. J., Salamov, A., Schwelm, A., Schijlen, E., Sun, H., van den Burg, H. A., van Ham, R. C., Zhang, S., Goodwin, S. B., Grigoriev, I. V., Collemare, J., and Bradshaw, R. E. 2012. The genomes of the fungal plant pathogens Cladosporium fulvum and Dothistroma septosporum reveal adaptation to different hosts and lifestyles but also signatures of common ancestry. PLoS Genet. 8: e1003088.

Deng, Y., Zhai, K., Xie, Z., Yang, D., Zhu, X., Liu, J., Wang, X., Qin, P., Yang, Y., Zhang, G., Li, Q., Zhang, J., Wu, S., Milazzo, J., Mao, B., Wang, E., Xie, H., Tharreau, D., and He, Z. 2017. Epigenetic regulation of antagonistic receptors confers rice blast resistance with yield balance. Science 355:962-965.

Dixon, R. A., Achnine, L., Kota, P., Liu, C. J., Reddy, M. S., and Wang, L. 2002. The phenylpropanoid pathway and plant defence-a genomics perspective. Mol. Plant Pathol. 3:371-390.

Dong, Y., Li, Y., Zhao, M., Jing, M., Liu, X., Liu, M., Guo, X., Zhang, X., Chen, Y., Liu, Y., Liu, Y., Ye, W., Zhang, H., Wang, Y., Zheng, X., Wang, P., and Zhang, Z. 2015. Global genome and transcriptome analyses of Magnaporthe oryzae epidemic isolate 98-06 uncover novel effectors and pathogenicity-related genes, revealing gene gain and lose dynamics in genome evolution. PLoS Pathog. 11:e1004801.

dos Santos, R. F., Spósito, M. B., Ayres, M., and Sosnowski, M. 2018a. In vitro production of conidia of Elsinoë ampelina, the causal fungus of grapevine anthracnose. Eur. J. Plant Pathol. 152:815-821.

dos Santos, R. F., Spósito, M. B., Ayres, M. R., and Sosnowski, M. R. 2018b. Phylogeny, morphology and pathogenicity of Elsinoë ampelina, the causal agent of grapevine anthracnose in Brazil and Australia. J. Phytopathol. 166:187-198.

Emanuelsson, O., Nielsen, H., Brunak, S., and von Heijne, G. 2000. Predicting subcellular localization of proteins based on their N-terminal amino acid sequence. J. Mol. Biol. 300:1005-1016.

Fan, X. L., Barreto, R. W., Groenewald, J. Z., Bezerra, J. D. P., Pereira, O. L., Cheewangkoon, R., Mostert, L., Tian, C. M., and Crous, P. W. 2017. Phylogeny and taxonomy of the scab and spot anthracnose fungus Elsinoë (Myriangiales, Dothideomycetes). Stud. Mycol. 87:1-41.

Feng, B. Z., Zhu, X. P., Fu, L., Lv, R. F., Storey, D., Tooley, P., and Zhang, X. G. 2014. Characterization of necrosis-inducing NLP proteins in Phytophthora capsici. BMC Plant Biol. 14:126.

Fröbel, S., Dudenhöffer, J., Töpfer, R., and Zyprian, E. 2019. Transcriptome analysis of early downy mildew (Plasmopara viticola) defense in grapevines carrying the Asian resistance locus Rpv10. Euphytica 215:28.

Fung, R. W., Gonzalo, M., Fekete, C., Kovacs, L. G., He, Y., Marsh, E., McIntyre, L. M., Schachtman, D. P., and Qiu, W. 2008. Powdery mildew induces defense-oriented reprogramming of the transcriptome in a susceptible but not in a resistant grapevine. Plant Physiol. 146: 236-249.

Gao, M., Wang, Q., Wan, R., Fei, Z., and Wang, X. 2012. Identification of genes differentially expressed in grapevine associated with resistance to Elsinoe ampelina through suppressive subtraction hybridization. Plant Physiol. Biochem. 58:253-268.

Gao, M., Zhu, Y., Yang, J., Zhang, H., Cheng, C., Zhang, Y., Wan, R., Fei, Z., and Wang, X. 2019. Identification of the grape basic helix-loop-helix transcription factor family and characterization of expression patterns in response to different stresses. Plant Growth Regul. 88:19-39.

Glazebrook, J. 2005. Contrasting mechanisms of defense against biotrophic and necrotrophic pathogens. Annu. Rev. Phytopathol. 43: 205-227.

Gostinčar, C., Ohm, R. A., Kogej, T., Sonjak, S., Turk, M., Zajc, J., Zalar, P., Grube, M., Sun, H., Han, J., Sharma, A., Chiniquy, J., Ngan, C. Y., Lipzen, A., Barry, K., Grigoriev, I. V., and Gunde-Cimerman, N. 2014. Genome sequencing of four Aureobasidium pullulans varieties: Biotechnological potential, stress tolerance, and description of new species. BMC Genomics 15:549.

Guo, C., Guo, R., Xu, X., Gao, M., Li, X., Song, J., Zheng, Y., and Wang, X. 2014. Evolution and expression analysis of the grape (Vitis vinifera $\mathrm{L}$.) WRKY gene family. J. Exp. Bot. 65:1513-1528

Guo, Q., Major, I. T., and Howe, G. A. 2018. Resolution of growth-defense conflict: Mechanistic insights from jasmonate signaling. Curr. Opin. Plant Biol. 44:72-81.

Haddadi, P., Ma, L., Wang, H., and Borhan, M. H. 2016. Genome-wide transcriptomic analyses provide insights into the lifestyle transition and effector repertoire of Leptosphaeria maculans during the colonization of Brassica napus seedlings. Mol. Plant Pathol. 17: 1196-1210.

Heath, M. C., and Heath, I. B. 1971. Ultrastructure of an immune and a susceptible reaction of cowpea leaves to rust infection. Physiol. Plant Pathol. 1:277-287. 
Heller, J., and Tudzynski, P. 2011. Reactive oxygen species in phytopathogenic fungi: Signaling, development, and disease. Annu. Rev. Phytopathol. 49:369-390.

Hemetsberger, C., Herrberger, C., Zechmann, B., Hillmer, M., and Doehlemann, G. 2012. The Ustilago maydis effector Pep1 suppresses plant immunity by inhibition of host peroxidase activity. PLoS Pathog. 8: e1002684.

Horton, P., Park, K. J., Obayashi, T., Fujita, N., Harada, H., Adams-Collier, C. J., and Nakai, K. 2007. WoLF PSORT: Protein localization predictor. Nucleic Acids Res. 35 (Web Server):W585-W587.

Hou, H., Li, J., Gao, M., Singer, S. D., Wang, H., Mao, L., Fei, Z., and Wang, X. 2013. Genomic organization, phylogenetic comparison and differential expression of the SBP-box family genes in grape. PLoS One 8:e59358.

Jeffress, S., Arun-Chinnappa, K., Stodart, B., Vaghefi, N., Tan, Y. P., and Ash, G. 2020. Genome mining of the citrus pathogen Elsinoë fawcettii; prediction and prioritisation of candidate effectors, cell wall degrading enzymes and secondary metabolite gene clusters. PLoS One 15: e0227396.

Joung, J. G., Corbett, A. M., Fellman, S. M., Tieman, D. M., Klee, H. J., Giovannoni, J. J., and Fei, Z. 2009. Plant MetGenMAP: An integrative analysis system for plant systems biology. Plant Physiol. 151: 1758-1768.

Jwa, N. S., and Hwang, B. K. 2017. Convergent evolution of pathogen effectors toward reactive oxygen species signaling networks in plants. Front. Plant Sci. 8:1687.

Kono, A., Nakaune, R., Yamada, M., Nakano, M., Mitani, N., and Ueno, T. 2009. Effect of culture conditions on conidia formation by Elsinö̈ ampelina, the causal organism of grapevine anthracnose. Plant Dis. 93 : 481-484.

Kono, A., Sato, A., Ban, Y., and Mitani, N. 2013. Resistance of Vitis germplasm to Elsinö̈ ampelina (de Bary) Shear evaluated by lesion number and diameter. HortScience 48:1433-1439.

Lan, X., Liu, Y., Song, S., Yin, L., Xiang, J., Qu, J., and Lu, J. 2019. Plasmopara viticola effector PvRXLR131 suppresses plant immunity by targeting plant receptor-like kinase inhibitor BKI1. Mol. Plant Pathol. 20:765-783.

Li, N., Lin, B., Wang, H., Li, X., Yang, F., Ding, X., Yan, J., and Chu, Z. 2019. Natural variation in ZmFBL41 confers banded leaf and sheath blight resistance in maize. Nat. Genet. 51:1540-1548.

Li, T., Wang, Q., Feng, R., Li, L., Ding, L., Fan, G., Li, W., Du, Y., Zhang, M., Huang, G., Schäfer, P., Meng, Y., Tyler, B. M., and Shan, W. 2019. Negative regulators of plant immunity derived from cinnamyl alcohol dehydrogenases are targeted by multiple Phytophthora Avr3a-like effectors. New Phytol. nph.16139.

Li, Z., Dang, H., Yuan, X., He, J., Hu, Z., and Wang, X. 2018. Morphological characterization and optimization of conditions for conidial production of Elsino $\ddot{e}$ ampelina, the causal organism of grapevine anthracnose. J. Phytopathol. 166:420-428.

Li, Z., Fan, Y., Chang, P., Gao, L., and Wang, X. 2020. Genome sequence resource for Elsino $\ddot{e}$ ampelina, the causal organism of grapevine anthracnose. Mol. Plant-Microbe Interact 33:576-579.

Li, Z., Zhang, H., and Li, G. 2019a. Characterization of phytotoxin and secreted proteins identifies of Lasiodiplodia theobromae, causes of peach gummosis. Fungal Biol. 123:51-58.

Li, Z., Zhang, S., Han, R., Zhang, H., Li, K., and Wang, X. 2019b. Infection process and host responses to Elsinö̈ ampelina, the causal organism of grapevine anthracnose. Eur. J. Plant Pathol. 155:571-582.

Liao, H. L., and Chung, K. R. 2008. Cellular toxicity of elsinochrome phytotoxins produced by the pathogenic fungus, Elsino $\ddot{e}$ fawcettii causing citrus scab. New Phytol. 177:239-250.

Liu, R., Weng, K., Dou, M., Chen, T., Yin, X., Li, Z., Li, T., Zhang, C., Xiang, G., Liu, G., and Xu, Y. 2019. Transcriptomic analysis of Chinese wild Vitis pseudoreticulata in response to Plasmopara viticola. Protoplasma 256:1409-1424.

Liu, Y., Lan, X., Song, S., Yin, L., Dry, I. B., Qu, J., Xiang, J., and Lu, J. 2018. In planta functional analysis and subcellular localization of the oomycete pathogen Plasmopara viticola candidate RXLR effector repertoire. Front. Plant Sci. 9:286.

Livak, K. J., and Schmittgen, T. D. 2001. Analysis of relative gene expression data using real-time quantitative PCR and the $2^{-\Delta} \Delta \mathrm{C}(\mathrm{T})$ method. Methods 25:402-408.

Lo Presti, L., Lanver, D., Schweizer, G., Tanaka, S., Liang, L., Tollot, M., Zuccaro, A., Reissmann, S., and Kahmann, R. 2015. Fungal effectors and plant susceptibility. Annu. Rev. Plant Biol. 66:513-545.

Louime, C., Lu, J., Onokpise, O., Vasanthaiah, H. K., Kambiranda, D., Basha, S. M., and Yun, H. K. 2011. Resistance to Elsinoë ampelina and expression of related resistant genes in Vitis rotundifolia Michx. grapes. Int. J. Mol. Sci. 12:3473-3488.
Love, M. I., Huber, W., and Anders, S. 2014. Moderated estimation of fold change and dispersion for RNA-seq data with DESeq2. Genome Biol. 15:550.

Magarey, R. D., Coffey, B. E., and Emmett, R. W. 1993. Anthracnose of grapevines, a review. Plant Prot. Quart. 8:106-110.

Magarey, R. D., Emmett, R. W., Magarey, P. A., and Franz, P. R. 1993. Evaluation of control of grapevine anthracnose caused by Elsinoe ampelina by pre-infection fungicides. Australas. Plant Pathol. 22:48-52.

Mirzadi Gohari, A., Ware, S. B., Wittenberg, A. H., Mehrabi, R., Ben M'Barek, S., Verstappen, E. C., van der Lee, T. A., Robert, O., Schouten, H. J., de Wit, P. P. J. G. M., and Kema, G. H. J. 2015. Effector discovery in the fungal wheat pathogen Zymoseptoria tritici. Mol. Plant Pathol. 16: 931-945.

Möbius, N., and Hertweck, C. 2009. Fungal phytotoxins as mediators of virulence. Curr. Opin. Plant Biol. 12:390-398.

Nguyen Ba, A. N., Pogoutse, A., Provart, N., and Moses, A. M. 2009. NLStradamus: A simple Hidden Markov Model for nuclear localization signal prediction. BMC Bioinformatics 10:202.

Petersen, T. N., Brunak, S., von Heijne, G., and Nielsen, H. 2011. SignalP 4.0: Discriminating signal peptides from transmembrane regions. Nat. Methods 8:785-786.

Pezzuto, J. M. 2008. Grapes and human health: A perspective. J. Agric. Food Chem. 56:6777-6784.

Poolsawat, O., Tharapreuksapong, A., Wongkaew, S., Chaowiset, W., and Tantasawat, P. 2012. Laboratory and field evaluations of resistance to Sphaceloma ampelinum causing anthracnose in grapevine. Australas. Plant Pathol. 41:263-269.

Poolsawat, O., Tharapreuksapong, A., Wongkaew, S., Reisch, B., and Tantasawat, P. 2010. Genetic diversity and pathogenicity analysis of Sphaceloma ampelinum causing grape anthracnose in Thailand. J. Phytopathol. 158:837-840.

Qi, T., Guo, J., Liu, P., He, F., Wan, C., Islam, M. A., Tyler, B. M., Kang, Z., and Guo, J. 2019. Stripe rust effector PstGSRE1 disrupts nuclear localization of ROS-promoting transcription factor TaLOL2 to defeat ROS-induced defense in wheat. Mol. Plant 12:1624-1638.

Rovenich, H., Boshoven, J. C., and Thomma, B. P. 2014. Filamentous pathogen effector functions: Of pathogens, hosts and microbiomes. Curr. Opin. Plant Biol. 20:96-103.

Rudd, J. J., Kanyuka, K., Hassani-Pak, K., Derbyshire, M., Andongabo, A., Devonshire, J., Lysenko, A., Saqi, M., Desai, N. M., Powers, S. J., Hooper, J., Ambroso, L., Bharti, A., Farmer, A., Hammond-Kosack, K. E., Dietrich, R. A., and Courbot, M. 2015. Transcriptome and metabolite profiling of the infection cycle of Zymoseptoria tritici on wheat reveals a biphasic interaction with plant immunity involving differential pathogen chromosomal contributions and a variation on the hemibiotrophic lifestyle definition. Plant Physiol. 167: 1158-1185.

Santos, R. F., Ciampi-Guillardi, M., Amorim, L., Massola Júnior, N. S., and Spósito, M. B. 2017. Aetiology of anthracnose on grapevine shoots in Brazil. Plant Pathol. 67:692-706.

Santos, R. F., and Spósito, M. B. 2018. Improving assessments of anthracnose severity on grapevine leaves through the development of a standard area diagram set. Australas. Plant Pathol. 47:357-364.

Schoch, C. L., Shoemaker, R. A., Seifert, K. A., Hambleton, S., Spatafora, J. W., and Crous, P. W. 2006. A multigene phylogeny of the Dothideomycetes using four nuclear loci. Mycologia 98:1041-1052.

Shanmugam, G., Jeon, J., and Hyun, J. W. 2020. Draft genome sequences of Elsinö fawcettii and Elsinö̈ australis causing scab diseases on citrus. Mol. Plant-Microbe Interact 33:135-137.

Sperschneider, J., Dodds, P. N., Gardiner, D. M., Manners, J. M., Singh, K. B., and Taylor, J. M. 2015. Advances and challenges in computational prediction of effectors from plant pathogenic fungi. PLoS Pathog. 11: e1004806.

Stergiopoulos, I., and de Wit, P. J. 2009. Fungal effector proteins. Annu. Rev. Phytopathol. 47:233-263.

Tanaka, E., Kumagawa, T., Ito, N., Nakanishi, A., Ohta, Y., Suzuki, E., Hamada, A., Ashizawa, T., Ohara, T., and Tsuda, M. 2017. Colonization of the vegetative stage of rice plants by the false smut fungus Villosiclava virens, as revealed by a combination of species-specific detection methods. Plant Pathol. 66:56-66.

Tao, S. Q., Auer, L., Morin, E., Liang, Y. M., and Duplessis, S. 2020. Transcriptome analysis of apple leaves infected by the rust fungus Gymnosporangium yamadae at two sporulation stages. Mol. PlantMicrobe Interact 33:444-461.

Thind, T. S., Arora, J. K., Mohan, C., and Raj, P. 2004. Epidemiology of powdery mildew, downy mildew and anthracnose diseases of grapevine. Pages 621-638 in: Diseases of Fruits and Vegetables. S. A. M. H. Naqvi, ed. Kluwer Academic Publishers, Dordrecht, Netherlands. 
Trapnell, C., Roberts, A., Goff, L., Pertea, G., Kim, D., Kelley, D. R., Pimentel, H., Salzberg, S. L., Rinn, J. L., and Pachter, L. 2012. Differential gene and transcript expression analysis of RNA-seq experiments with TopHat and Cufflinks. Nat. Protoc. 7:562-578.

Urban, M., Cuzick, A., Rutherford, K., Irvine, A., Pedro, H., Pant, R., Sadanadan, V., Khamari, L., Billal, S., Mohanty, S., and HammondKosack, K. E. 2017. PHI-base: A new interface and further additions for the multi-species pathogen-host interactions database. Nucleic Acids Res. 45:D604-D610.

Valent, B., and Khang, C. H. 2010. Recent advances in rice blast effector research. Curr. Opin. Plant Biol. 13:434-441.

van de Mortel, J. E., de Vos, R. C., Dekkers, E., Pineda, A., Guillod, L., Bouwmeester, K., van Loon, J. J. A., Dicke, M., and Raaijmakers, J. M. 2012. Metabolic and transcriptomic changes induced in Arabidopsis by the rhizobacterium Pseudomonas fluorescens SS101. Plant Physiol. 160:2173-2188.

Vleeshouwers, V. G., and Oliver, R. P. 2014. Effectors as tools in disease resistance breeding against biotrophic, hemibiotrophic, and necrotrophic plant pathogens. Mol. Plant-Microbe Interact 27:196-206.

Wan, R., Hou, X., Wang, X., Qu, J., Singer, S. D., Wang, Y., and Wang, X. 2015. Resistance evaluation of Chinese wild Vitis genotypes against Botrytis cinerea and different responses of resistant and susceptible hosts to the infection. Front. Plant Sci. 6:854.

Wang, L., Hu, X., Jiao, C., Li, Z., Fei, Z., Yan, X., Liu, C., Wang, Y., and Wang, X. 2016. Transcriptome analyses of seed development in grape hybrids reveals a possible mechanism influencing seed size. BMC Genomics 17:898.

Wang, N., Zheng, Y., Xin, H., Fang, L., and Li, S. 2013. Comprehensive analysis of NAC domain transcription factor gene family in Vitis vinifera. Plant Cell Rep. 32:61-75.

Wang, Q., Han, C., Ferreira, A. O., Yu, X., Ye, W., Tripathy, S., Kale, S. D., Gu, B., Sheng, Y., Sui, Y., Wang, X., Zhang, Z., Cheng, B., Dong, S.,
Shan, W., Zheng, X., Dou, D., Tyler, B. M., and Wang, Y. 2011. Transcriptional programming and functional interactions within the Phytophthora sojae RXLR effector repertoire. Plant Cell 23:2064-2086.

Wang, Y., Liu, Y., He, P., Lamikanra, O., and Lu, J. 1998. Resistance of Chinese Vitis species to Elsinoe ampelina (de Bary) shear. HortScience 33:123-126.

Yang, D. L., Yao, J., Mei, C. S., Tong, X. H., Zeng, L. J., Li, Q., Xiao, L. T., Sun, T. P., Li, J., Deng, X. W., Lee, C. M., Thomashow, M. F., Yang, Y., He, Z., and He, S. Y. 2012. Plant hormone jasmonate prioritizes defense over growth by interfering with gibberellin signaling cascade. Proc. Natl. Acad. Sci. U.S.A. 109:E1192-E1200.

Yin, L., An, Y., Qu, J., Li, X., Zhang, Y., Dry, I., Wu, H., and Lu, J. 2017. Genome sequence of Plasmopara viticola and insight into the pathogenic mechanism. Sci. Rep. 7:46553.

Zhang, Y., Zhang, K., Fang, A., Han, Y., Yang, J., Xue, M., Bao, J., Hu, D., Zhou, B., Sun, X., Li, S., Wen, M., Yao, N., Ma, L. J., Liu, Y., Zhang, M., Huang, F., Luo, C., Zhou, L., Li, J., Chen, Z., Miao, J., Wang, S., Lai, J., Xu, J. R., Hsiang, T., Peng, Y. L., and Sun, W. 2014. Specific adaptation of Ustilaginoidea virens in occupying host florets revealed by comparative and functional genomics. Nat. Commun. 5:3849.

Zhu, Y., Li, Y., Zhang, S., Zhang, X., Yao, J., Luo, Q., Sun, F., and Wang, X. 2019. Genome-wide identification and expression analysis reveal the potential function of ethylene responsive factor gene family in response to Botrytis cinerea infection and ovule development in grapes (Vitis vinifera L.). Plant Biol. 21:571-584.

Zuluaga, A. P., Vega-Arreguín, J. C., Fei, Z., Matas, A. J., Patev, S., Fry, W. E., and Rose, J. K. 2016. Analysis of the tomato leaf transcriptome during successive hemibiotrophic stages of a compatible interaction with the oomycete pathogen Phytophthora infestans. Mol. Plant Pathol. 17: 42-54. 